\title{
SOME OBSERVATIONS ON CONGENITAL DISLOCATION OF THE HEAD OF THE RADIUS
}

\author{
D. E. Caravias, Sheffield, England \\ From the Orthopaedic Department of the City General Hospital, Sheffield
}

During a study of the late results of fractures of the neck and head of the radius in children reduced by conservative or open reduction, my attention was attracted to a patient whose radiographs reminded me of the two cases of congenital dislocation of the head of the radius that $I$ have seen.

The purpose of this paper is to suggest certain conclusions that might be drawn from a comparison of this case of traumatic dislocation with the two of congenital dislocation of the head of the radius.

\section{CASE REPORTS}

Case 1-A boy aged fourteen years attended the hospital after sustaining an injury to his left elbow in a fall. Radiographs showed a posterior dislocation of the left elbow, with a fracture of the neck of the radius. The proximal fragment was tilted forwards and laterally. The proximal epiphysis of the radius was not yet fused to the shaft, as it should be at this age, and it looked undamaged (Fig. 1). The dislocation of the elbow was reduced and a manipulative reduction of the fracture of the neck of the radius was attempted. Although the reduction was not complete it was considered adequate. A collar and cuff was applied for about seven weeks. When it was removed the range of elbow movement was from 165 degrees to 75 degrees; pronation and supination were limited by two-thirds. Apart from active movements and normal use no further treatment was considered necessary. Two years later the range of movement was from 175 degrees to 70 degrees; supination was about half the normal and pronation was limited by a third.

When he was seen four years after the injury for the purpose of this review movements were as follows: extension full, flexion to 60 degrees, supination absent and pronation limited by a third. Ability to lift weights and to screw and unscrew was diminished. The head of the radius could be felt in the lateral part of the cubital fossa, and during pronation it seemed to rotate in a small arc around the ulna. Radiographs four years after the injury showed the head of the radius to be deformed and dislocated forwards and laterally (Fig. 2). The part between the head and the bicipital tuberosity of the radius was elongated. The head of the radius was not articulating with the humerus, and it was dome shaped rather than concave on its upper surface. The capitulum, which was normally developed at the time of the injury (Fig. 1), was now deformed. A backward spur from the radial shaft, at the level of the bicipital tuberosity, looked like the postero-medial margin of the fracture surface of the distal fragment of the radius. In the place of the proximal radio-ulnar joint there was a gap. Case 2-A woman aged thirty-six years attended because she had sustained an injury to her right elbow ten days previously. She stated that she had injured the same elbow at the age of five. On examination the head of the radius could be felt in an abnormal position and it constituted the most lateral point of the elbow. It was slipping over the outer edge of the humerus, as the elbow was flexed. Extension and flexion of the elbow were full. Pronation was full but supination was limited by a third. Radiographs showed a picture often described as characteristic of congenital dislocation of the head of the radius (Fig. 3). The head of the radius was dome shaped and dislocated backwards and laterally. The ulna was thicker than normal in its uppermost third and bowed backwards and to the radial side. Instead of the anterior curve of the posterior outline of the ulna in its uppermost 

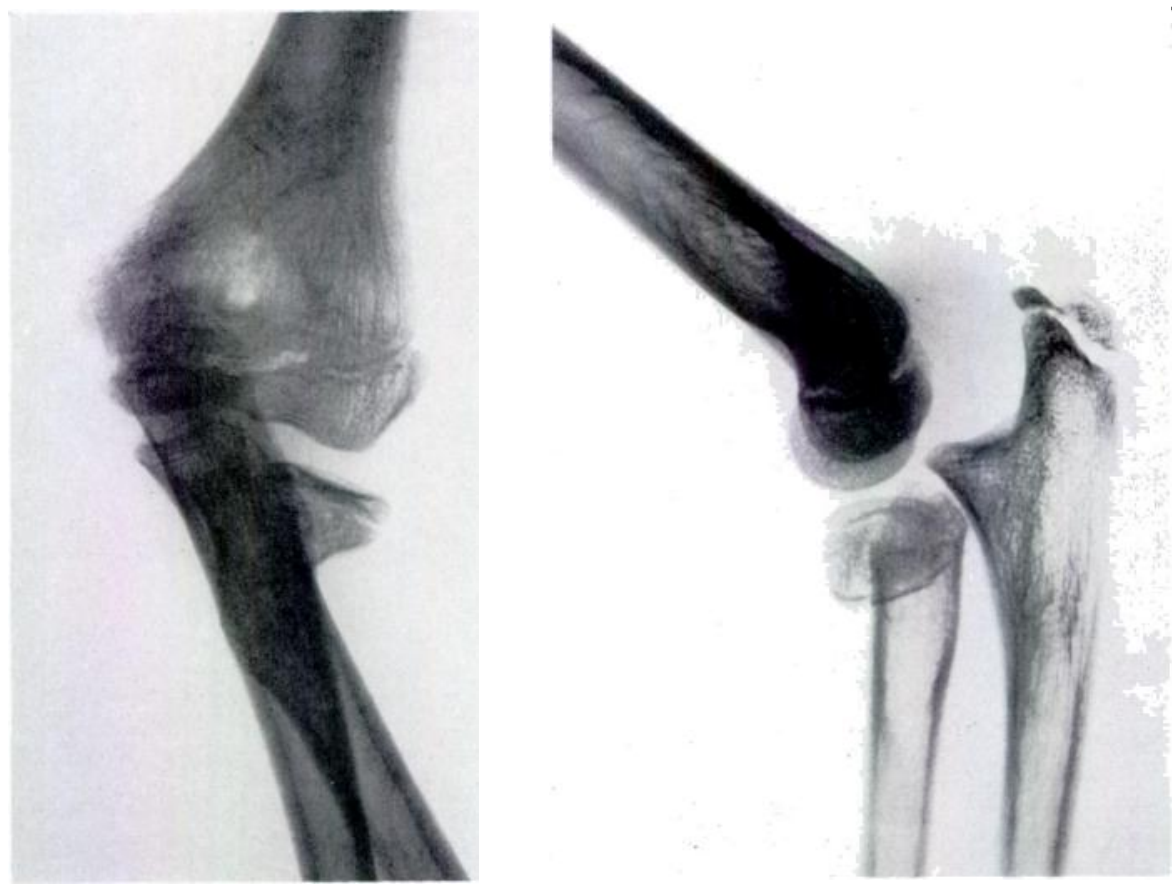

FIG. 1

Case 1-Radiographs of left elbow at the time of the injury.

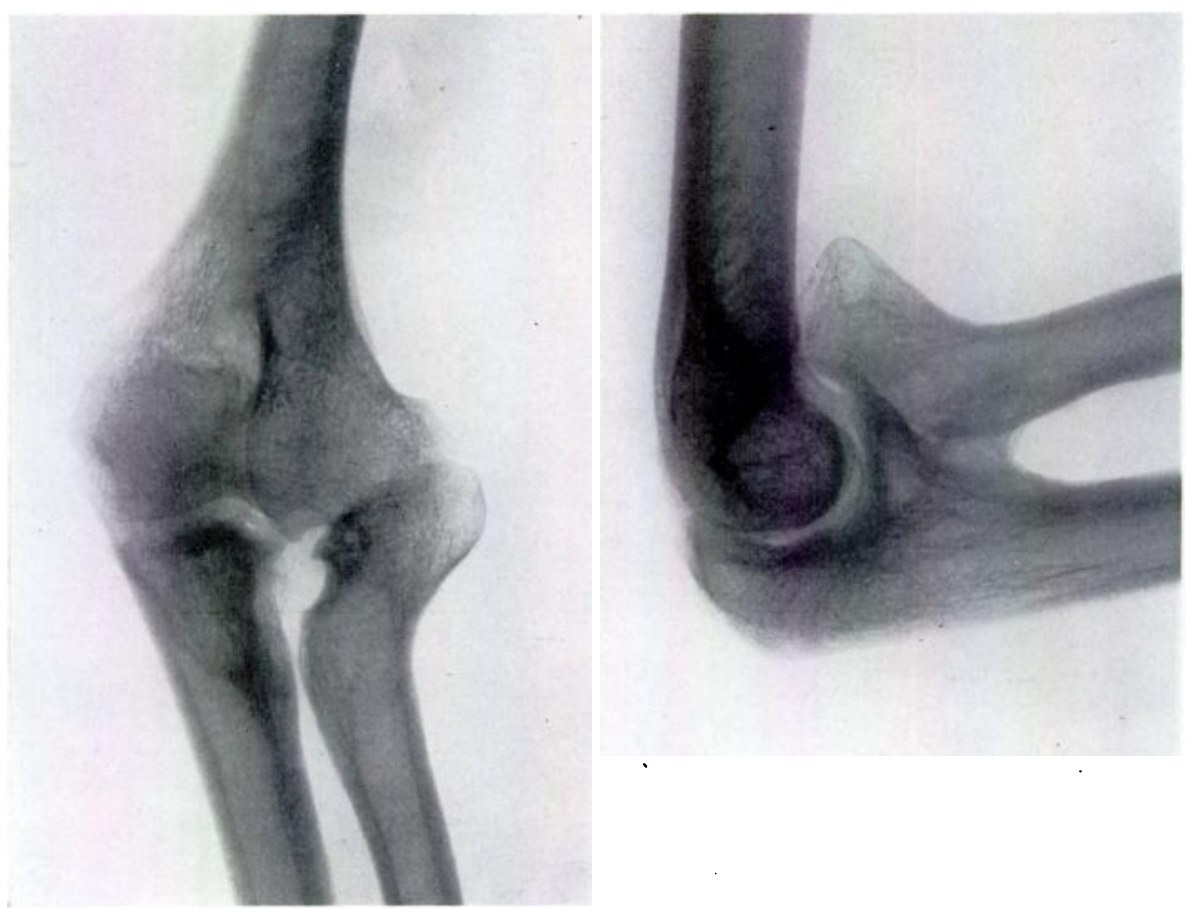

Fig. 2

Case 1-Radiographs of the same elbow four years later.

VOL. 39 B, NO. 1, FEBRUARY 1957 
third, as described by McFarland (1936), there was an exaggeration of the normal posterior curve. In place of the backward sweep from the coronoid process there was a smooth curved line. The capitulum was deformed, having an oblique shallow depression

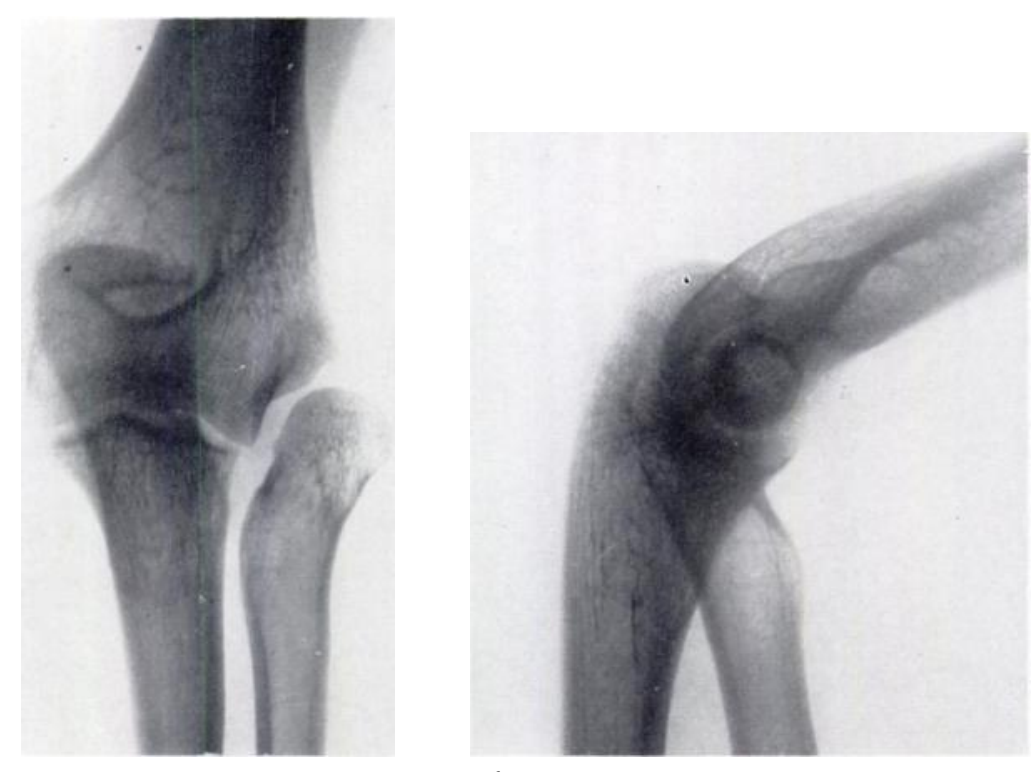

FIG. 3

Case 2--Radiographs of right elbow showing changes characteristic of congenital dislocation of the head of the radius.
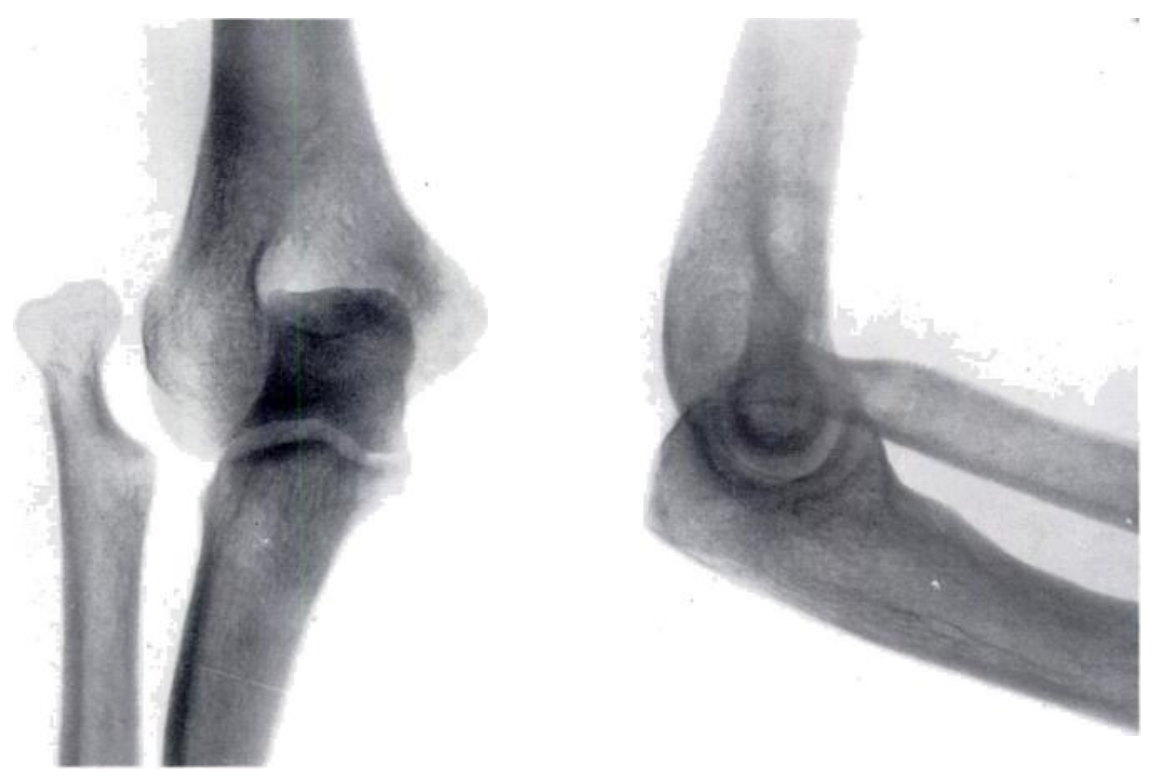

Fig. 4

Case 3-Radiographs of right elbow showing congenital dislocation of the head of the radius.

on its outer aspect, with which the deformed radial head appeared to articulate. Since the patient had no disability apart from slight limitation of supination, no treatment was indicated. Case 3-A girl of eighteen attended complaining of pain in her right elbow after a fall. She 
said she had never been able to supinate the right forearm, nor had she been able to straighten the elbow completely. Her father stated that since her birth, which was a normal one, there had been an extra lump of bone on the outer side of the elbow, and that when she was two weeks old she had been sent for physiotherapy because there was not much use in the right arm. Clinically the head of the right radius was dislocated laterally. Extension was to 140 degrees. Flexion and pronation were full. Supination was absent. The hand and the arm appeared to have developed normally and there was no sign of Erb's palsy.

Radiographic examination showed that the upper ends of the radius and ulna were at the same level (Fig. 4). The head of the radius was dislocated laterally. It was dome shaped on its upper surface-presumably through lack of contact with the humerus-but otherwise it maintained its general structure in diminished form. The neck of the radius was present and at its medial surface there was a groove opposite the lateral epicondyle. The neck was not markedly angulated in relation to the radial shaft but maintained its normal angle. The upper half of the radial shaft was thinner than normal. The ulna had also been affected by the dislocation. It was thicker than normal at its upper end and bowed to the lateral side. The capitulum was ill-formed. There was no sign of a depression where the displaced head of the radius lay against the outer aspect of the humerus. There was no place in the lower end of the humerus which could bear an articular facet for articulation with the head of the radius. The widest gap between the radius and ulna was at the level of the superior radic-ulnar joint.

In order to increase the range of movement, the head of the radius, with the greater part of the neck, was excised (Fig. 5). The head was infantile and convex in its upper surface, with a little dimple in the centre uncovered by articular cartilage, whereas the rest of the head was covered by cartilage. The neck was represented by a circular, rather shallow groove. When the head was removed it was seen that it was lying in a false articular cavity formed by synovial membrane reinforced by thick fibrous tissue. The attachment of the synovial membrane was almost at a normal level around the neck.

After the operation the range of movement in the elbow was improved but the patient has not been able to attend for late follow-up examination.

\section{DISCUSSION}

Congenital dislocation of the head of the radius with no other congenital abnormality in the elbow is rare. I have found only twenty-five cases recorded in the literature.

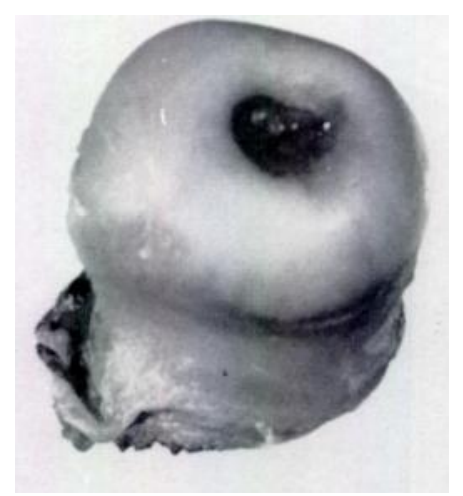

FIG. 5

Case 3-The excised head of radius. The photograph shows the superior surface and the postero-lateral aspect of the head and neck.

White (1943) mentioned twenty-one cases, of which eleven had been described by McFarland (1936), and added one more. Bindman (1945) reported a case of congenital recurrent dislocation of the radial head, and Magee (1947) described a case of a bilateral congenital dislocation. Osmond-Clarke (1948) considered it due to hypoplasia of the capitulum. Watson-Jones (1955) showed radiographs of one case.

In only two cases of the twenty-five was the dislocation recurrent and completely reducible. The dislocation was always anterior in these cases, but according to Osmond-Clarke the radial head is dislocated backwards more often than forwards. In the second of the cases reported here the head of the radius was dislocated backwards and laterally and in the third case laterally.

VOL. 39 B, NO. 1, FEBRUARY 1957 
In none of the reported cases was the condition noticed at or soon after birth. The third case reported here had a definite deformity at birth and this is in favour of a congenital origin of the dislocation. The fact that the dislocation was anterior in all the cases reported in the literature may possibly be explained by the fact that an anterior dislocation is often found in a Monteggia type of injury-that is in forced pronation.

The direction of bowing of the ulna depends upon the type of dislocation of the radial head. If an abnormal position is taken up by one of the bones of the forearm the other grows bent. In unreduced congenital or traumatic anterior dislocation of the radial head the ulna will bend forwards, in posterior dislocation of the head the ulna will bend backwards (Fig. 3), and in lateral dislocation the ulna will bend laterally (Fig. 4).

The anterior convexity of the ulna, described by McFarland (1936), is the type of deformity that one would expect to find in association with an unreduced traumatic anterior dislocation as well as with a congenital anterior dislocation of the head of the radius. In the second and third cases described here this anterior curve was not found because neither of these was an anterior dislocation. This anterior convexity must not be considered a pathognomonic sign of congenital dislocation of the head of the radius.

Ossification in the tissues about the radial head, referred to by some authors, is also found in unreduced traumatic dislocations of the radial head.

White (1943) suggested that some of the cases reported as anterior congenital dislocations of the radial head were traumatic in origin. In distinguishing between a congenital and a traumatic dislocation one of the most reliable signs is the condition of the capitulum: if this is grossly underdeveloped a congenital dislocation is suggested.

On this basis, taken in conjunction with the history of injury to the elbow at the age of five, it seems likely that the dislocation described in Case 2 was a post-traumatic rather than a congenital dislocation.

It is known that in congenital dislocation of the hip there is a failure of growth of the acetabulum. The head of the femur therefore grows abnormally, with abnormal curves in the neck, because it has not borne the normal stresses. Likewise in congenital dislocation of the head of the radius the primary defect may well be a failure of growth of the capitulum, and the altered shape of the head of the radius is a secondary deformity.

\section{SUMMARY}

1. Radiological criteria in the diagnosis of congenital dislocation of the head of the radius are suggested.

2. Some of the radiographic features described as characteristic of congenital dislocation of the head of the radius may be found also in post-traumatic dislocation of the radial head.

I am greatly indebted to Mr S. Pappworth for permission to publish these cases and for advice in the preparation of this paper.

\section{REFERENCES}

Bindman, E. (1945): Congenital Recurrent Dislocation of Head of Radius. British Medical Journal, ii, 354. MCFarland, B. (1936): Congenital Dislocation of the Head of the Radius. British Journal of Surgery, $24,41$. McFarland, B. (1950): In Modern Trends in Orthopaedics, p. 131. Edited by Sir Harry Platt. London: Butterworth \& Co. (Publishers) Ltd.

MAGEE, R. K. (1947): Bilateral Congenital Dislocation of Radial Head. Lancet, i, 519.

Osmond-Clarke, H. (1948): Deformities. In British Surgical Practice. Vol. 3, p. 180. Under the General Editorship of Sir Ernest Rock Carling and J. Paterson Ross. London: Butterworth \& Co. (Publishers) Ltd. Watson-Jones, Sir R. (1955): Fractures and Joint Injuries. Fourth Edition, II, 559. Edinburgh and London: E. \& S. Livingstone Ltd.

White, J. R. A. (1943): Congenital Dislocation of the Head of the Radius. British Journal of Surgery, $30,377$. 